\title{
Aprendizagem Colaborativa, Troca de Saberes e Redes Sociais: tríade na Educação Básica
}

\section{Everton Bedin}

bedin.everton@gmail.com

0000-0002-5636-0908

niversidade Luterana do Brasil, Canoas, Rio Grande do Sul, Brasil.

\section{RESUMO}

Este artigo apresenta resultados, como suporte aos ambientes de aprendizagem colaborativa à luz da Sustentabilidade Ambiental no Ensino Médio Politécnico, qualificados a partir das interações discentes em uma rede social, enfatizando os processos de ensino e aprendizagem de modo virtual, incorporando a participação dialógica e ativa dos discentes. Visou-se explorar, por meio das interações, as concepções que os mesmos apresentam sobre a Sustentabilidade Ambiental no viés das redes sociais. A metodologia abordada foi de cunho exploratório, partindo de uma pesquisa com perspectivas qualitativas e quantitativas. Os dados qualitativos foram analisados através da Análise Textual Discursiva e os dados quantitativamente foram representados pela Teoria de Grafos. O presente estudo constatou a solicitude da aprendizagem colaborativa e a abertura dos saberes dos discentes no que diz respeito às ações de cunho ambiental e que as mudanças podem prover projetos e ações educacionais que se apropriam dos recursos tecnológicos nas instituições de ensino.

PALAVRAS-CHAVE: Rede Social. Interação. Aprendizagem Colaborativa. 


\section{INTRODUÇÃO E APORTES TEÓRICOS}

Atualmente, de forma indiscutível, as Tecnologias Digitais de Informação e Comunicação (TDICs), além de passarem a ocupar um espaço significativo na sociedade como mecanismos de entretenimento, progressivamente são utilizadas pelos profissionais da educação como um paradigma técnico aliado aos processos de ensino e aprendizagem. A origem primordial nasce da conectividade exacerbada dos jovens com as mídias sociais, em compartilhar e ressignificar o conhecimento sociocultural com o conhecimento científico. Nesta esfera, as mídias sociais mais difundidas são as redes sociais, uma vez que cresce diariamente o número de pessoas que buscam a conexão com o mundo de forma virtual para compartilhar ou buscar novas informações no meio.

Pesquisas como as de Mansur et al. (2011) e Novais Souza e Schneider (2013, p. 220) já confirmaram este fato, pois esboçam que as redes sociais "não são fenômenos recente, nem tampouco surgiram com a Internet, mas sempre fizeram parte da sociedade, motivados pela busca do indivíduo por pertencimento, pela necessidade de compartilhar conhecimentos, informações e preferências".

Assim, ao trabalhar com a rede social no sentido de proliferação de informação e mecanismo de estudo e aprendizagem, propõe-se a ressignificação para o ensino, pois, segundo Santaella (2010, p. 118), "as redes nos livram das escalas micro e macro - família, grupo, instituições, nação - substituindo-as por conectividade. A hierarquia e o poder dão lugar a associações e conexões" e a interoperabilidade desses ambientes permite uma nova forma de condução dos processos de ensino e aprendizagem, tornando-os mais atraentes e significativos, uma vez que que apresentam inúmeras funcionalidades interativas que ampliam e modificam o contexto educacional, como colocado por Bedin e Barwaldt (2014).

Nesta perspectiva, Amiel (2012) reforça que as práticas pedagógicas e os recursos utilizados nos processos de ensino e aprendizagem partem de novos ambientes, tornando-os aptos à prática educativa. Ainda, Novais Souza e Schneider (2013, p. 221) corroboram que o professor tem à sua disposição "uma diversidade de ambientes que foram pensados inicialmente para trocas sociais interativas, como as redes sociais, mais precisamente o Facebook", isto é, múltiplos mecanismos que podem ser adaptáveis à utilização em sala de aula, como recursos didáticos e/ou ferramentas de aprendizagem a distância.

Neste desenho, a escola, enquanto mecanismo de formação ética, científica e tecnológica do aprendiz, não pode desassociar-se do mundo acadêmico que a cerca, logo, precisa fazer parte da realidade tecnológica que Ihe confere, multiplicando e qualificando o conhecimento aos estudantes nativos digitais. Neste desenho, profissionais da educação de diferentes modalidades de ensino buscam, incansavelmente, melhorias nas metodologias para canalizar as TDICs em sala de aula, a fim de que os alunos possam colaborar entre si e proporcionar competências e habilidades mínimas previstas nos Projetos Políticos Administrativos Pedagógicos.

Deste modo, vincular o ensino e a aprendizagem às tecnologias nas escolas públicas tem se tornado uma alternativa para levar o entretenimento ao estudante no momento da aprendizagem em contextos de formação institucional e não institucional, isto é, fora das salas de aula. Uma das vantagens de usar a rede neste processo, servindo como apoio para enriquecer momentos pedagógicos, é que a 
mesma apresenta uma multiplicidade de ferramentas de comunicação e trabalho, capaz de fazer com que os estudantes aprendam em meio à comunicação e a interatividade, uma vez que se estabelecem condições de suporte para a dinâmica necessária à colaboração e socialização coletiva.

Assim, o aprendiz que colabora com a movimentação de ideias e concepções no berço da rede promove a convivência e a transformação, tornando-se um aprendiz orgânico, espécie naturalmente aprendiz/aprendente, por meio da interação com o outro (SOUZA, 2009). Desta forma, percebe-se a influência positiva das interações na rede, pois estas possuem, de acordo com Harasim (2005, p. 50), várias características com o ensino presencial, dentre elas, "a apresentação de ideias, as discussões em classe, os debates e outras formas de construção de conhecimento através da interação e da troca".

Nesta teia, sabe-se que existem convivência e transformação de conhecimentos e de saberes no ambiente virtual durante as interações, já que os sujeitos se tornam autores do conhecimento que emerge na rede por meio das participações, contribuições e indagações, uma vez que é permitido às pessoas a conexão e reconexão a todo o momento. Assim, por meio das interações de elementos e conhecimentos, as pessoas buscam construir saberes para possibilitar um ensino e uma aprendizagem de formas ativa e colaborativa.

Percebe-se, desta forma, que os mecanismos informatizantes que possibilitam a troca de ideias e concepções nas redes promovem, de amplo ângulo, a aprendizagem colaborativa, pois aumenta a comunicação e a relação entre educando e educador, envolvendo, quase sempre, projetos de aprendizagem em grupo e a promoção da discussão, momento em que "os ambientes de aprendizagem, presenciais ou a distância, mediados pela oralidade, pela escrita, pelo debate e pela cooperação, permitem a criação de significados e sentidos" (SOUZA, 2009, p. 18).

Ao tocante, cabe destacar que, quando compreendidos como espaços reservados para trocas de saberes em prol da aprendizagem, as redes propiciam os desenvolvimentos social, cultural, crítico, educacional e imaginário do estudante, levando-o para além dos muros da escola, ultrapassando limites e barreiras por meio da inter-relação com o outro à luz das TDICs, as quais possuem ferramentas que possibilitam criar o contexto necessário à aprendizagem colaborativa, pois permitem a partilha e o aperfeiçoamento de conteúdos em múltiplos suportes.

Nesta perspectiva, as interações que ocorrem nas redes promovem a construção de saberes na ação colaborativa, pois, segundo a pesquisadora Souza (2006, p. 18), "deve-se refletir sobre a necessidade de construir um ambiente virtual onde se tenha como recursos promissores a colaboração e a cooperação dos indivíduos e, sobre quaisquer desafios, a eliminação das sensações de isolamento, desânimo, ansiedade e desmotivação".

Entretanto, sabe-se que trabalhar em prol da construção do saber virtualmente não é tarefa fácil, pois se necessita estímulos cognitivos e psicológicos. Neste desenho, Mendes-Netto e Perpétuo (2010, p. 10) fazem menção aos estudos de Jean Piaget (1962) quando afirmam que para o pleno desenvolvimento da aprendizagem o afeto e as relações sociais são fundamentais, já que o aluno é um ser social cuja inteligência é constituída a partir das suas experiências e pelo tipo de aprendizagem em que é submetido. Contudo, tais 
ações estão introduzidas nas mais diferentes relações sociais; logo, não podem ser desconsideradas em nenhuma modalidade de educação, virtual ou presencial.

Assim, a importância da utilização das redes sociais no viés das TDICs para a emersão da aprendizagem de forma colaborativa é a familiaridade que os estudantes possuem com a mesma, contribuindo de forma ativa com o desenvolvimento dos processos de ensino e aprendizagem; uma contribuição de todos os sujeitos envolvidos e não mais apenas do professor. Neste desenho, a atividade se torna importante e relevante na medida em que "a utilização das redes sociais mediadas pela Internet, além de proporcionarem um ambiente propício ao compartilhamento de informações, atualmente tem assumido um caráter interativo" (SILVA et al., 2014, p. 129).

Diante dos fatos, pode-se perceber que trabalhar de forma colaborativa nas redes sociais é um indicativo para mudar o modelo tradicional de ensinar e aprender, o qual se estipula como uma forma organizada, sintetizada, hierarquizada. A utilização das redes sociais para o aprendizado do educando sobre qualquer assunto, de cunho acadêmico/currículo escolar, é uma ação que vem sendo qualificada no momento atual, pois as TDICs atuam como uma prática de criatividade, sem uma metodologia definida e validada, para despertar o interesse e a curiosidade do aluno.

Neste âmbito, este trabalho tem por intuito apresentar como algumas práticas de cunho tecnológico (interações através das redes sociais) podem interferir na qualificação e emancipação dos processos de ensino e aprendizagem, considerando a necessidade das TDICs estarem entrelaçadas à didática do professor por meio de metodologias adaptadas a perspectiva de Projetos de Aprendizagem $^{1}$ (PAs).

Em concordância a essas concepções, o presente artigo visa abordar a questão da emersão de saberes discentes à luz da Sustentabilidade Ambiental por meio das interações nas redes sociais, uma vez que os discentes envolvidos são alunos do Ensino Médio Politécnico. Para tanto, para enriquecer a discussão sobre os resultados apresentados abaixo, se fez necessário pesquisar o estado da arte relacionado com o tema em questão; pesquisar TDICs voltadas às redes sociais; definir grupo de discentes a serem observados; deliberar categorias para as análises das interações; analisar resultados e, por fim, expressar e refletir os dados obtidos.

Assim, torna-se importante esclarecer que a utilização da metodologia de Projetos de Aprendizagem (PAs), como artefato enriquecedor ao desenvolvimento das atividades docentes, tem sua importância na medida em que propõe e cogita a interação e a troca de saberes e experiências entre os sujeitos envolvidos no processo de aprendizagem na rede. Neste sentido, Fagundes et al. (1999) afirmam que utilizar os PAs é proporcionar aos estudantes uma nova forma de aprendizagem diferente daquela apresentada nas escolas tradicionais, uma vez que, segundo Bedin (2016), esta metodologia tem, enquanto metodologia utilizada com competências e habilidades, a capacidade de "minimizar as ideias de transmissão de informação, auxiliando os sujeitos dos processos de ensino e aprendizagem a saída do comodismo" (BEDIN, 2016, p. 184). 
os sujeitos, além de favorecer o desenvolvimento de um processo dialético de construção do conhecimento, a fim de permitir ações que favoreçam a metodologia de aprender e ensinar por meio de atualizações cognitivas e pedagógicas. (BEDIN; DEL PINO, 2015, p. 799).

Ainda, segundo Bedin (2016), a ideia de utilizar os PAs para maximizar as aulas de forma cooperativa e formativa, além de diferenciar e propor uma nova forma de construção de conhecimento a partir da interação e da troca de experiências, possibilita "um processo de ação-reflexão continuado aos sujeitos da aprendizagem" (BEDIN, 2016, p. 193). Portanto, a metodologia de PAs "visa a compreensão do outro e o respeito mútuo entre as pessoas como fonte de desenvolvimento social, cultural e interpessoal" (BEDIN, 2016, p. 195), pois faz com que o professor assuma "um papel de instigador da inteligência coletiva dos grupos de pesquisas com os quais interage, centrando sua atividade no acompanhamento e na gestão das aprendizagens" (BEDIN; DEL PINO, 2015, p. 799).

\section{DESENHO E PLANEJAMENTO DA PESQUISA}

Os relatos que fazem parte desta análise de dados emergiram de uma pesquisa desenvolvida sobre a perspectiva do uso das TDICs em prol da qualificação dos processos de ensino e aprendizagem à luz da Sustentabilidade Ambiental, isto é, uma atividade docente em função da aprendizagem colaborativa na teia da metodologia de PAs, incluída na disciplina de Seminário Integrado no currículo das escolas estaduais do estado do RS, no sul do Brasil, após a reestruturação curricular.

O desígnio do presente ensaio foi agrupado à Sustentabilidade Ambiental, tema gerador do segundo ano do Ensino Médio Politécnico de uma escola pública, em um município rural do norte do estado do Rio Grande do Sul. A temática emergiu a partir de pesquisas sócio antropológicas elaboradas pelos segmentos escolares, a fim de investigar um tema, de importância e relevância ao contexto dos discentes, como eixo norteador para o planejamento e desenvolvimento das atividades docentes de formas interdisciplinar, formativa e emancipatória.

Considera-se Sustentabilidade Ambiental um tema relativo ao município, haja vista que este, basicamente, possui $50 \%$ da população (4.000 habitantes) que vive e sobrevive no/do campo; logo, se torna relevante e importante para os discentes entenderem e refletirem sobre os reais motivos da Sustentabilidade Ambiental sobre o arquétipo cultural. Corroborando, Neumann e Loch (2002, p. 248) apontam para a "necessidade em desenvolver mecanismos e instrumentos de gestão ambiental; capazes em responder aos problemas relacionados com o contexto social, econômico e agroecológico adequados às diferentes categorias e atores sociais presentes no rural".

O docente responsável pela disciplina, ao desenvolver o planejamento em sala de aula, sugeriu leituras sobre a temática por meio de PAs, proporcionando troca de saberes e interações em sala de aula. Posteriormente, através da análise de Redes Sociais, foi possível compreender e acompanhar de forma mais eficaz a disseminação das informações e a interação entre o grupo composto na rede, com base nas leituras de Oliveira et al. (2012).

Destaca-se que as interações que premiaram na rede originaram-se por meio dos conhecimentos específicos da área das Ciências da Natureza ${ }^{2}$ em relação à 
Sustentabilidade Ambiental, uma vez que, para Rezende (2002, p. 02), "o uso das tecnologias pode contribuir para práticas pedagógicas desde que seja baseado em concepções de conhecimento [...]". Neste âmbito, a perspectiva de adentrar com os PAs na sala de aula passou a ser considerada norteadora ao vínculo do saber, pois se utilizou como um mecanismo para estimular e instigar a curiosidade do educando; "utilizar PAs é modificar a metodologia costumeira e tradicional da sala de aula atual" (FAGUNDES; SATO; MAÇADA, 1999, p. 3).

Os dados que foram obtidos para análise neste trabalho emergiram deste grupo de discussão fechado na rede, realizado pelo professor da disciplina mencionado anteriormente. As discussões se constituíram por quatro meses e, ao mesmo tempo, foram analisadas e qualificadas. Os meses selecionados para a coleta dos dados foram semelhantes aos que o professor desenvolveu as atividades referentes à temática de cunho avaliativo.

Para explicitação empírica do assunto, fizeram-se referências às revisões bibliográficas, concepções e percepções que os estudantes construíram sobre a temática durante a realização do trabalho, ou seja, a análise parte do ponto de vista do pesquisador e os dados se referem à atividade do grupo. Neste meio, pode-se qualificar o determinado trabalho como exploratório, pois Gil $(2008$, p. 42) revela que "a pesquisa exploratória proporciona maior familiaridade com o problema, podendo envolver levantamento bibliográfico, entrevistas com pessoas experientes no problema pesquisado e/ou com a comunidade local". 0 autor ainda explica que na pesquisa descritiva a descrição sobre as características de determinadas populações ou fenômenos leva em consideração que uma de suas peculiaridades está na utilização de técnicas padronizadas de coleta de dados, tais como: o questionário e a observação sistemática.

\section{RESULTADOS E DISCUSSÕES}

Os resultados apresentados a seguir foram analisados no decorrer e no término da aplicação da atividade através de uma rede social, o Facebook, por ser mais difundida e aceita nos meios acadêmicos. As interações foram desenvolvidas por estudantes com faixa etária semelhante, de escolaridade homogênea e de diversas etnias e afazeres. O grupo foi realizado em ambiente fechado, preservando os dados obtidos, assim como a identidade, as concepções, percepções e ideias dos mesmos.

O trabalho se desenvolveu com o auxílio do pesquisador e também professor da disciplina de Seminário Integrador a partir da temática mencionada. Com o intuito de trabalhar com as TDICs fora do ambiente escolar, foi construído um grupo fechado com os estudantes do segundo ano do Ensino Médio Politécnico para dar continuidade aos trabalhos desenvolvidos em sala de aula, a fim de instigar os mesmos a trabalharem criticamente frente à temática por meio da emersão da aprendizagem colaborativa sobre Sustentabilidade Ambiental. Para este estudo, optou-se em apresentar a qualificação sobre uma das questões que o professor realizou na rede, analisando-a de forma qualitativa e quantitativa.

A questão selecionada para a qualificação, considerando maior número de interações, foi: qual a relação existente entre Sustentabilidade Ambiental e Ciências da Natureza? A análise quantitativa desta questão foi representada pela Teoria de Grafos através da ferramenta UCINET ${ }^{3}$; técnica de representações 
gráficas para visualização em rede. Simplificadamente, um grafo é constituído de várias conexões de nós ( $\mathrm{n}$ ) e de ligações (I).

A mesma é capaz de distinguir atores e ligações, bem como redes direcionais e não-direcionais. Neste desenho, a Teoria de Grafos está sendo empregada cada vez mais em análises de redes sociais, pois possui boa capacidade de representação e simplicidade, observados em Grunspan, Wiggins e Goodreau (2014). Deste modo, o uso de grafos se faz necessário para interpretar de forma quantitativa a relação entre os sujeitos envolvidos no grupo da rede. Quanto menor o grafo, mais facilmente se representa a totalidade das características dos atributos da rede. A noção de rede demonstra um conjunto de nós interconectados (CASTELLS, 1999), onde esses nós podem ser pessoas, grupos ou outras unidades, e as interconexões são relações; conjuntos de laços que respeitam um mesmo critério de relacionamento.

Em consonância com as palavras de Recuero (2009, p. 27), reforça-se que "por meio da observação se pode aprender sobre os atores e observar as interações e conexões entre eles, já que todo o tipo de desenho de pessoas pode ser tomado como um nó da rede social". Observando-se a figura 1 abaixo, é possível perceber o grau de interação na rede durante a pesquisa.

Neste viés, é importante mencionar que cada quadrado azul no grafo corresponde a um discente, variando de 02 a 43 . O quadrado verde é considerado o docente e o vermelho a questão analisada. É perceptível reconhecer os nós e os vínculos no grafo (discentes e suas interações). Destaca-se, para amplitude de análise, as ligações do estudante 05 , uma vez que este se relaciona integramente com os estudantes 16, 20, 24, 27 e com o docente. Em contrapartida, a discente 22 se relaciona somente com o docente, mas recebe críticas, sugestões e complementações de sua fala dos discentes 05, 09, 17, 34 e 38, conforme é mostrado, detalhadamente, na figura do grafo. As indicações entre os sujeitos são percebidas por meio da ponta de seta.

Figura 1 - Grafo das interações entre os discentes e o docente.

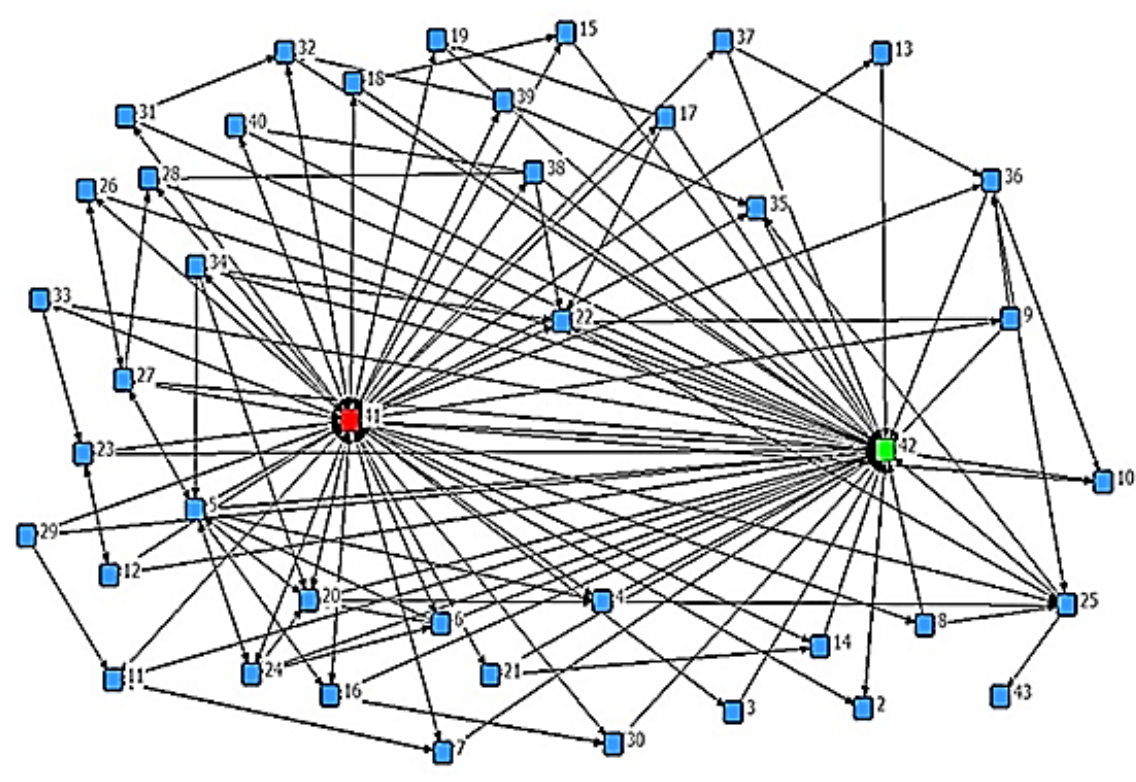


Também, ao analisar o grafo, é possível ver que sua densidade (medição da quantidade de ligações existentes) é baixa; o grafo apresenta uma baixa relação entre as pessoas. Ao calcular a densidade ideal deste grafo chegou-se ao resultado de 1.482 relações, mas a densidade real apresenta uma média de 74 relações. Essa densidade é resultado da relação que existe entre os nós e os vértices. Quando o grafo apresenta uma baixa densidade, significa que o mesmo apresenta baixa conectividade entre os nós; grafos com densidades altas apresentam uma altíssima conexão entre os nós.

Contudo, ressalva-se que, como o intuito deste trabalho era avaliar a relação dialógica entre os sujeitos emergentes no grafo, o ideal, segundo Santos (2013, p. 32), é usá-lo com uma baixa densidade, tornando-se viável avaliar a relação entre os nós, pois a conexão entre eles é perceptível a olho nu. Abaixo na figura 2, a fórmula para uma melhor compreensão do cálculo, considerando que a densidade (D) de uma rede é definida como uma relação entre o número de arestas (E) para o número de arestas possíveis, dada pelo coeficiente binomial (N/2).

Figura 2 - Fórmula utilizada para cálculo da densidade.

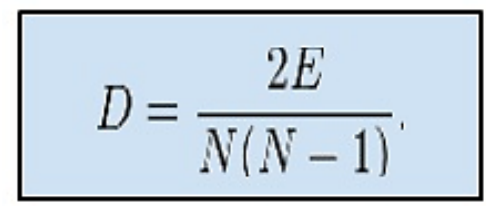

Fonte: O autor (2016)

Neste viés de interações, percebe-se que a atividade realizada com os alunos foi organizada de forma a despertar nos mesmos o interesse pelo assunto, uma vez que o começo da atividade, intercalando a temática com as pesquisas no viés dos PAs, atraiu a atenção dos alunos para estudar e decifrar enigmas sociais e culturais da realidade local à luz da Sustentabilidade Ambiental. Assim, a análise da Teoria de Grafos ofereceu a oportunidade de avaliar e compreender o diálogo discente e as interações cooperativas e colaborativas que emergiam na rede.

Da mesma forma, entende-se que esta atividade é um fator relevante no Ensino Médio, pois faz menção a temas atuais da ciência e da tecnologia; logo, o advento das TDICs reavivou as práticas de ensino-aprendizagem devido à flexibilidade do tempo, quebra de barreiras espaciais, emissão e recebimento instantâneo de materiais. Assim, além de permitir a realização das tradicionais formas mecanicistas de transmitir conteúdos, agora digitalizados e hipermediáticos, se proporcionou a exploração do potencial de interatividade das TDICs com base na interação e na produção de conhecimento.

Todavia, torna-se importante compreender que não basta inserir os alunos em grupos de redes sociais para que ocorram interações significativas em torno de temáticas coerentes com as intenções da atividade em realização, neste caso específico Sustentabilidade Ambiental, nem tampouco se pode admitir que o acesso a hipertextos e recursos multimediáticos dê conta da complexidade dos processos educacionais, haja vista que utilizar as TDICs como suporte a maximização de fontes de informações, problemas e objetos de conhecimento, muitas vezes, acaba por não ser satisfatório para envolvê-los e despertar nos mesmos a motivação pela aprendizagem. 
Nesta perspectiva, entende-se que as TDICs devem ser usadas como materiais didáticos de apoio aos processos de ensino e aprendizagem, de forma a enriquecer a aprendizagem do educando. As interações apresentadas nas redes sociais, por exemplo, foram, apesar de o grafo apresentar uma densidade baixa, ricas e satisfatórias, pois a atividade desenvolvida com o auxílio do professor permitiu ao estudante criar procedimentos pessoais que Ihe permitiram a organização do próprio tempo para estudos e participação na atividade.

Portanto, as redes sociais na Internet são reconhecidas como agrupamentos complexos instituídos por interações sociais apoiadas em tecnologias digitais de comunicação. A metáfora da rede é mobilizada, em seu trabalho, para pensar os aspectos individuais, coletivos e tecnológicos dos agrupamentos humanos na Internet. Esse instrumental revela padrões de conexão em cujas pontas estão as pessoas que utilizam os terminais de acesso, historicamente situadas (RECUERO, 2009).

Em relação a análise qualitativa da questão elencada pelo professor na rede, utilizou-se a Análise Textual Discursiva (ATD) como ferramenta analítica para qualificá-la. A ATD é um processo que se inicia com uma unitarização das escrituras na rede para capturar palavras semelhantes que levam a emersão de categorias, decorrentes de bases teóricas estudadas em Barwaldt, Felipe e Adamatti (2012) e Preece (2005). Emergiram, após a unitarização, cinco categorias como forma de facilitar a compreensão e a associação das ideias, concepções e percepções dos estudantes.

Destaca-se que a ATD tem sido utilizada como um encaminhamento metodológico para a realização de pesquisas por Galiazzi (2003) e Gonçalves e Marques (2006). Assim, entende-se que esta metodologia contribui para a identificação e análise das concepções subentendidas na rede pelos estudantes no viés da Sustentabilidade Ambiental.

Ainda, compreende-se que a qualificação de análise sobre interações, indiferente do meio de coleta de dados, deve ser por meio da ATD, "uma abordagem de análise de dados que transita entre duas formas consagradas de análise na pesquisa qualitativa: a análise de conteúdo e a análise de discurso" (MORAES; GALIAZZI, 2006, p. 118). Neste aporte, entende-se que a ATD é uma técnica de análise textual qualitativa, que se volta para a produção de compreensões aprofundadas e criativas de um determinado assunto, requerendo um envolvimento intenso com as informações do corpus $^{4}$ da análise.

Exige uma impregnação aprofundada com os elementos do processo analítico. Somente essa impregnação intensa possibilita uma leitura válida e pertinente das interações na rede. Fazer uma análise rigorosa é, portanto, um exercício de ir além de uma leitura superficial, possibilitando uma construção de novas compreensões e teorias a partir de um conjunto de informações sobre determinados fenômenos (MORAES, 2003).

Portanto, a categorização, além de reunir elementos semelhantes, também "implica nomear e definir as categorias, cada vez com maior precisão, na medida em que vão sendo construídas" (MORAES, 2003, p. 195). Nesta categorização existe um retorno cíclico; momento em que há construção gradativa do significado de cada categoria emergida. Neste processo, assumem-se denominações iniciais, intermediárias e, posteriormente, as finais, aquelas em que se contemplam, realmente, as concepções implícitas na rede. 
A figura 3 demonstra, em percentagem, as concepções dos estudantes sobre o trabalho construído na rede referente à questão analisada.

Figura 3 - Categorias emergidas a partir da ATD.

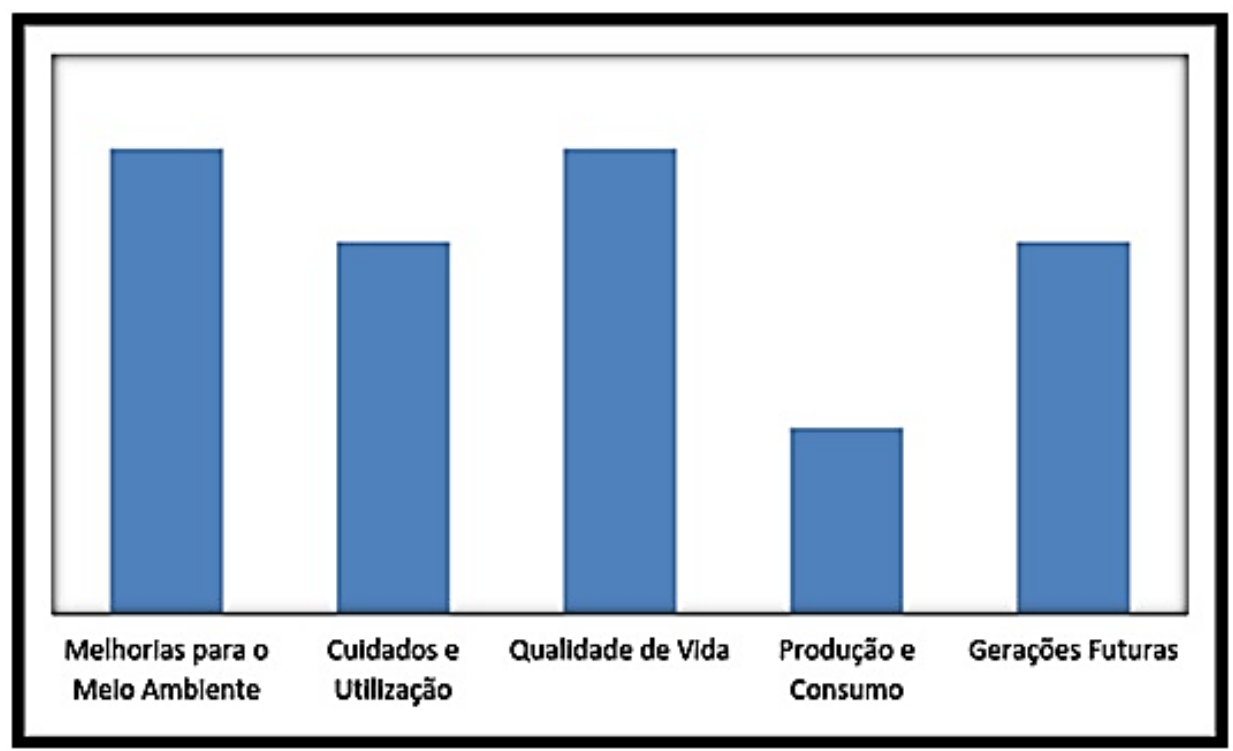

Fonte: O autor (2016)

Percebe-se que as categorias Melhorias para o Meio Ambiente e Qualidade de Vida são as principais ideias de relação entre Sustentabilidade Ambiental e Ciências da Natureza, pois obtiveram $25 \%$ de pontuação cada uma, totalizando $50 \%$ das publicações dos estudantes. Em outras palavras, quando mencionado o elo que existe entre Ciências da Natureza e Sustentabilidade Ambiental, 25\% dos estudantes credibilizam a ideia de que o mesmo favorece a qualidade de vida e/ou uma melhoria para o meio ambiente. Em seguida, encontram-se as categorias Cuidado e Utilização e Gerações Futuras, com 21\%, totalizando 42\% dos estudantes, restando, com um percentual de $8 \%$, a categoria Produção e Consumo.

Acredita-se que este resultado tenha derivado das leituras disponibilizadas pelo professor em sala de aula, antes do desenvolvimento da atividade na rede, pois um dos textos-base, proporcionados pelo docente para leitura e compreensão maior sobre os aportes teóricos e práticos da Sustentabilidade Ambiental, caracterizava-a como um mecanismo para buscar a valorização da vida, a formação de um novo estilo de vida, sem consumismo excessivo, sem o desperdício de recursos e sem a degradação ambiental, garantindo o futuro das novas gerações, encontrados em Pelicioni (1998) e Herculano (1992).

Corroborando, Reigota (1994) reflete que o meio ambiente exige que a Educação Ambiental defronte o desafio da mudança de mentalidade sobre as ideias de modelo de desenvolvimento baseado na acumulação econômica, no autoritarismo político, no saque aos recursos naturais, no desprezo às culturas de grupos minoritários e aos direitos fundamentais do homem.

Outro motivo relevante à emersão dessas categorias diz respeito aos Projetos desenvolvidos com o auxílio dos PAs, pois os estudantes buscavam, dentro da temática, ramificar conhecimentos e saberes sobre aquilo que lhes era importante. Muitos buscavam ampliar, trocar e ressignificar conhecimentos sobre lixo orgânico, água, reciclagem, assuntos que estão ao encontro das categorias 
emergidas na rede; logo, os estudantes, no momento de interagir e trocar ideias na rede, frequentemente traziam concepções acerca do que estavam pesquisando e desenvolvendo teoricamente na disciplina de Seminário Integrado.

Diante dos fatos esboçados, percebe-se que é importante trabalhar de forma colaborativa questões de cunho ambiental nas escolas, indiferentemente da forma em que se propõe a trabalhar, tornando-se sagaz lembrar que, quando se trabalha com as tecnologias, principalmente em ambientes virtuais do tipo redes sociais, é necessário que o docente tenha competências e habilidades para promover um diálogo de interesse mútuo nas informações, onde os discentes possam trocar ideias e experiências com o intuito de argumentar e defender seus saberes.

Assim, é preciso perceber que as interações podem ocorrer de diversas formas e mudar a complexidade do cenário, por exemplo, na própria sala de aula, com toda a sua dinâmica, percebe-se o quanto tais interações entre os sujeitos assumem diferentes perfis. Um deles, apresentado neste artigo, diz respeito às práticas em que a tecnologia atua como mediadora do processo educacional. $\mathrm{O}$ cerne na educação tecnológica e no próprio ensino presencial é o mesmo: a inserção das TDICs para a contribuição nos processos de ensino e aprendizagem em diferentes níveis de interatividade, antes não existentes, facilitados pelas novas tecnologias.

Desta forma, é contingente reforçar que, com o avanço das interações na rede, é possível perceber que os estudantes desenvolvem autonomia e controle sobre os próprios comentários. Assim, percebe-se que o desenvolvimento do diálogo que ocorre no berço das tecnologias assume uma posição crítica, autônoma e, quiçá, contextualizada em relação ao Meio Ambiente e a Sustentabilidade Ambiental

\section{CONSIDERAÇÕES FINAIS}

Este artigo apresentou paradigmas docentes vinculadas ao uso das tecnologias, como forma de favorecer os processos de ensino e aprendizagem de forma colaborativa à luz da metodologia de PAs, proporcionando uma reflexão sobre a utilização das TDICs em ambientes virtuais do tipo redes sociais, a fim de entender as concepções, ideias, percepções e interações dos estudantes sobre a temática Sustentabilidade Ambiental. Pretendeu-se, também, favorecer o elo existente entre a formação discente e o uso das tecnologias em prol do desenvolvimento ético, reflexivo e crítico dos mesmos, em ambientes de aprendizagens configurados em assunto de caráter social e cultural e valorizar o contexto digital frente as questões de coletivismo e construtivismo.

Neste desenho, parte-se do pressuposto de que o profissional da educação é um transformador da realidade e que, na medida do possível, deve buscar a qualificação enquanto pesquisador e multiplicador de ações promotoras de direitos e deveres humanos. Por isso, corroborando com a formação contínua, o professor deve ser motivado a incorporar em suas práticas rotineiras as TDICs, pois se pensa que esta é uma maneira adequada de contribuir com as atividades educativas sobre a ação da teoria-prática, unida a ideia de que práxis significa a interpretação do mundo como guia de uma transformação por meio de ações e pensamentos humanos da aprendizagem colaborativa. 
O impacto da utilização das interações nas redes sociais para a construção de saberes e conhecimentos no coletivo por parte dos estudantes, por deveras, se considerou positivo e pertinente, pois, a partir da ação e do desenvolvimento do trabalho com a participação dos sujeitos envolvidos nesta questão, se criou uma expectativa a mais para os futuros ambientes de aprendizagem, uma vez que se configurou de forma diferente à incentivar o educando para debater assuntos atualizados de cunho crítico e científico.

Torna-se, também, relevante ressaltar que, com o desenvolvimento do trabalho, muitas ideias e concepções foram lapidadas, uma vez que estudantes que não interagiam em sala de aula no ambiente presencial, durante a troca de saberes nas redes sociais, de forma crítica e reflexiva, expuseram suas ideias e concepções acerca da temática. Do mesmo modo, o trabalho foi enriquecedor ao proporcionar aos estudantes a metodologia de Projeto de Aprendizagem com o apoio às tecnologias. Além disto, os estudantes foram autores da própria construção do conhecimento e construíram de forma autônoma a aprendizagem individual e coletiva em meio às interações dialógicas, desfrutando das tecnologias para encontrar a excelência de aprender em meio ao entretenimento críticoreflexivo.

Por fim, cabe ressaltar que o trabalho proporcionou o surgimento de conceitos mais reflexivos de avaliar a questão de Sustentabilidade Ambiental em relação às atividades desenvolvidas na área de Ciências da Natureza, propondo o desenvolvimento sustentável como um fator social, econômico, político e educacional. Portanto, é necessário um arcabouço político e social mais ágil, capaz de entender a imperativa necessidade de se trabalhar com as tecnologias e a introdução de novas formas e atitudes que priorizem temas relevantes e abrangentes como o meio ambiente nas suas mais distintas instâncias, compondo alternativas viáveis de avanço cultural com significativos benefícios à sociedade e as futuras gerações trabalhadas e vinculadas ao contexto educacional atual 


\title{
Collaborative Learning, Knowledge Exchange and Social Networks: triad in Basic Education
}

\begin{abstract}
This article presents results, to support collaborative learning environments considering the Environmental Sustainability Polytechnic High School, qualified students from interactions on a social network, emphasizing the teaching and learning processes virtual mode, incorporating will dialogical participation and activates the students. It aimed to explore, through the interactions, the views they present on Environmental Sustainability the bias of social networks. The methodology addressed was exploratory, starting from a search with qualitative and quantitative perspectives. Qualitative data were analyzed using Textual Analysis of Discourse and the data were quantitatively represented by Graph Theory. The present the study found in the solicitude of collaborative learning and the opening of knowledge of students about the actions of an environmental nature and that changes can provide projects and educational actions take ownership of technological resources in educational institutions.
\end{abstract}

KEYWORDS: Social Network. Interaction. Collaborative Learning 
1. O projeto de aprendizagem é uma pedagogia construtivista que tem como propósito promover o aprendizado através de um enfoque baseado em indagações para engajar os discentes com questões e conflitos que sejam reais e relevantes às suas vidas, visíveis quando o aluno apresenta algo a oferecer, o conhecimento prévio interage com o desconhecido, e assim apropriar-se dos conhecimentos específicos referentes a escola.

2. Área do conhecimento em que o professor da disciplina Seminário Integrado faz parte.

3. Link para download: https://sites.google.com/site/ucinetsoftware/downloads.

4. Toda análise textual concretiza-se a partir de um conjunto de documentos denominado corpus. Esse conjunto representa as informações da pesquisa e para a obtenção de resultados válidos e confiáveis, requer uma seleção e delimitação rigorosa. Seguidamente não trabalhamos com todo o corpus, mas é necessário definir uma amostra a partir de um conjunto maior de textos. (BARDIN, 1997).

\section{REFERÊNCIAS}

AMIEL, T. Educação Aberta: Configurando ambientes, práticas e recursos educacionais. In: SANTANA, B. ROSSINI, C. PRETTO, N. L. (org.) REA: Práticas colaborativas e políticas públicas. São Paulo: Casa da Cultura Digital; Salvador: Edufba. 2012.

BARDIN, L. Análise de Conteúdo. Lisboa: Edições 70, 1997.

BARWALDT, R.; FELIPE, C. I.; ADAMATTI, D. The Accessibility at University by Assistive Technologies. In: II Congreso Internacional de Computación e Informática, 2012, Ciudad del Carmen. CONACI 2012. Berlin: Springer, 2012.

BEDIN, E. Seminário integrado e projeto de aprendizagem: um caminho seguro para a docência cooperativa e a interdisciplinaridade no ensino médio politécnico. Scientia Tec: Revista de Educação, Ciência e Tecnologia do IFRS Campus Porto Alegre, Porto Alegre, v.3, n.1, p. 180-201, jan/jun 2016. Disponível em: <https://periodicos.ifrs.edu.br/index.php/ScientiaTec/article/view/1475>. Acesso em: 20 de mar. 2017.

BEDIN, E. DEL PINO, J. C. Seminário Integrado e Projetos de Aprendizagem: uma proposta metodológica para a construção de saberes. Ciência e Natura, Santa Maria, v. 37 n. 3 set-dez. 2015, p. 796-807. Disponível em: <https://periodicos.ufsm.br/cienciaenatura/article/view/17245> Acesso em: 20 de mar. 2017. 
BEDIN, E.; BARWALDT, R. Tecnologia da Informação e Comunicação no contexto escolar: interações à luz da sustentabilidade ambiental no viés das redes sociais. RENOTE. Revista Novas Tecnologias na Educação, v. 12, p. 1-10, 2014.

CASTELLS, M. A sociedade em rede. São Paulo: Paz e Terra, 1999.

FAGUNDES, L.; SATO, L.; MAÇADA, D. Aprendizes do Futuro: as inovações começaram! Coleção Informática para a mudança na Educação. Brasília, MEC, 1999. Disponível em:

<http://www.dominiopublico.gov.br/download/texto/me003153.pdfs Acesso em: 20 de mar. de 2016.

GALIAZZI, M. C. Educar pela pesquisa: ambiente de formação de professores de Ciências. ljuí: UNIJUII, 2003.

GIL, A. Como elaborar projetos de pesquisa. 4. ed. São Paulo: Atlas, 2008.

GONÇALVES, P.; MARQUES, C. A. Contribuições pedagógicas e epistemológicas em textos de experimentação no ensino de química. Investigações em Ensino de Ciências, vol.11, n. 2, 2006. Disponível em: <https://www.if.ufrgs.br/cref/ojs/index.php/ienci/article/view/494/297>. Acesso em 15 de jan. 2016.

GRUNSPAN, Z.; WIGGINS, B. L.; GOODREAU, S. M. Understanding Classrooms through Social Network Analysis: A Primer for Social Network Analysis in Education Research, 2014. Disponível em: http://www.lifescied.org/content/13/2/167.short. Acesso em: 20 de abr. 2016.

HARASIN, L.; et al. Redes de Aprendizagem: Um guia para ensino e aprendizagem on-line. Tradução de Ibraíma Dafonte Tavares. São Paulo: Editora SENAC, 2005.

HERCULANO, S. C. Do desenvolvimento (in)sustentável à sociedade feliz. In: E, VIOLA.; et al. Ecologia ciência e política: participação social, interesses em jogo e luta de ideias no movimento ecológico. Rio de Janeiro, Devan, 1992. p. 9-15.

MANSUR, A. F. U.; GOMES, E. L.; CARVALHO, R. A.; BIAZUS, M. C. V. Cloud Education: Aprendizagem Colaborativa em Nuvem através do Kindle e de Redes Sociais. In: VI CITA - Congresso Iberoamericano de Telemática, 2011, Gramado. Cadernos de Informática. Porto Alegre: UFRGS, 2011. v. 6. p. 1-8. 
Educação a Distância 2010, Foz do Iguaçu. Anais. Foz do Iguaçu: ABED, 2010. 10p. Disponível em: <www.abed.org.br/congresso2010/cd/252010085045.pdf>. Acesso em: 13 fev. 2016.

MORAES, R.; GALIAZZI, M. C. Análise Textual Discursiva: processo reconstrutivo de múltiplas faces. Ciência \& Educação, v. 12, n. 1, p. 117-128, 2006. Disponível em: <http://www.scielo.br/pdf/ciedu/v12n1/08.pdf>. Acesso em: 28 mar. de 2016.

MORAES, R. Uma tempestade de luz: a compreensão possibilitada pela Análise Textual Descritiva. Ciência \& Educação, v. 9, n. 2, p. 191-211, 2003. Disponível em: <http://dx.doi.org/10.1590/S1516-73132003000200004>. Acesso em 18 de jan. 2016.

NOVAIS SOUZA, A. A.; SCHNEIDER, H. N. Uso do Facebook como Recurso de Avaliação da Aprendizagem. In: Il Congresso Brasileiro de Informática na Educação, XIX Workshop de Informática na Escola, 2013. Disponível em: <http://www.br-ie.org/pub/index.php/wie/article/view/2643/2297>. Acesso em: 02 de abri. 2016.

NEUMANN, P. S.; LOCH, C. Legislação Ambiental, Desenvolvimento Rural e Práticas Agrícolas. Ciência Rural, Santa Maria, vol. 32, n. 2, 2002, p. 243-249. Disponível em: <http://www.scielo.br/scielo.php?script=sci_arttext\&pid=S010384782002000200010>. Acesso em: 20 de jan. 2016.

OLIVEIRA, R.; ARAÚJO, J.; MEDEIROS, F.; BRITO, A. Monitoramento das Interações dos Aprendizes na Rede Social Twitter como Apoio ao Processo de Mediação Docente. In: Brazilian Workshop on Social Network Analysisand Mining, BrasNAM, XXXII Congresso da Sociedade Brasileira de Computação, CSBC, Curitiba, PR, 2012.

PELICIONI, M. V. Educação ambiental, qualidade de vida e sustentabilidade. Saúde e Sociedade, v. 7, no. 2, 1998. Disponível em:

<http://www.scielo.br/pdf/sausoc/v7n2/03.pdf>. Acesso em: 20 jan. 2016.

PREECE, J. Design de Interações: além da interação homem-computador. Tradução Viviane Possamai, Porto Alegre: Bookman, 2005.

PIAGET, J. A Relação da afetividade com a inteligência no desenvolvimento mental da criança. Vol, 26. no 3, 1962. 
REIGOTA, M. O que é educação ambiental. Cortez, São Paulo, 1994.

REZENDE, F. As novas tecnologias na prática pedagógica sob a perspectiva construtivista. ENSAIO: Pesquisa em Educação em Ciências. v. 02. № 1. mar, 2002.

SANTAELLA, L. A ecologia pluralista da comunicação, conectividade, mobilidade, ubiquidade. São Paulo: Ed. Paulus, 2010.

SANTOS, L. Otimização de fluxos em grafo. Trabalho de graduação, apresentado para obtenção do grau de bacharel em ciência da computação da Universidade Federal do Paraná, UFPR. 2013. Disponível em:

<http://www.inf.ufpr.br/andre/files/LeonardoSantos2013.pdf>. Acesso em: 10 jan. 2016.

SILVA, J. C.; BRITO, A. V.; MAHON, F.; MEDEIROS, F. P. Análise das interações dos alunos com Conteúdos e Atividades em Ambientes Colaborativos Virtuais de Aprendizagem. In: III Congresso Brasileiro de Informática na Educação, XXV Simpósio Brasileiro de Informática na Educação, 2014. p. 129-133. Disponível em: <http://www.br-ie.org/pub/index.php/sbie/article/view/2938/2672>. Acesso em: 3 de abr. 2016.

SOUZA, A. (org.). Comunidade de Trabalho e Aprendizagem em Rede. Brasília: Universidade de Brasília, 2009.

SOUZA, S. Confio em ambientes virtuais de aprendizagem. 2006. Laboratório de Educação Digital, Universidade Jean Piaget de Cabo Verde. Disponível em: <http://bdigital.unipiaget.cv:8080/jspui/bitstream/123456789/167/1/Confio\%20 em\%20ambientes\%20virtuais\%20de\%20aprendizagem.pdf>. Acesso em: 13 abr. 2016.

Recebido: 2016-04-28

Aprovado: 2017-03-27

DOI: $10.3895 /$ rbect.v10n2.3922

Como citar: BEDIN, E. Aprendizagem Colaborativa, Troca de Saberes e Redes Sociais: tríade na Educação

Básica. Revista Brasileira de Ensino de Ciência e Tecnologia, v. 10, n. 2, 2017. Disponível em:

$<$ https://revistas.utfpr.edu.br/rbect/article/view/3922>. Acesso em: xxx.

Correspondência:

Direito autoral: Este artigo está licenciado sob os termos da Licença Creative Commons-Atribuição 4.0

Internacional. 